\title{
Electrophoretic Mobility of Red Blood Cells and Micronucleus Test in Exfoliated Buccal Cells as Stress Intensity Markers
}

\author{
Anna V. Deryugina, $\mathrm{PhD}, \mathrm{ScD}^{1}$; Marina N. Ivashchenko, $\mathrm{PhD}^{2 *}$; Pavel S. Ignatyev, $\mathrm{PhD}^{3}$; \\ Marina V. Zolotova, $\mathrm{PhD}^{1}$; Aleksandr G. Samodelkin, $\mathrm{PhD}, \mathrm{ScD}^{2}$ \\ ${ }^{1}$ Lobachevsky State University of Nizhny Novgorod, Nizhny Novgorod, Russia \\ ${ }^{2}$ Nizhny Novgorod State Agricultural Academy, Nizhny Novgorod, Russia \\ ${ }^{3}$ Production Association «Urals Optical \& Mechanical Plant» n.a. E.S. Yalamov, Ekaterinburg, Russia
}

\begin{abstract}
The purpose of this study was to investigate the electrophoretic mobility of red blood cells (RBCs), cytomorphological and cytogenetical indices in exfoliated buccal epithelial cells of rats during the development of stress reaction.

Experiments were carried out on 60 white non-pedigree pubescent rats weighing 180-220 g. For stress modeling, the animals of experimental groups received a single intraperitoneal injection of epinephrine hydrochloride solution $(0.1 \mathrm{mg} / \mathrm{kg})$ or injections for 3 days of the experiment. Both the single and the repeated adrenalin injections provoked a decrease in the level of the RBC electrophoretic mobility. With a single adrenalin injection, the changes in RBC electrophoretic mobility are not so abrupt, with the subsequent development of the adaptive response and reparation of cytogenetic damage. With repeated adrenalin injections, the changes in RBC electrophoretic mobility are abrupt, and the number of pathological epithelial cells increases. (International Journal of Biomedicine. 2018;8(4):347-350.)
\end{abstract}

Key Words: red blood cells $\bullet$ electrophoretic mobility $\bullet$ buccal cells $\bullet$ stress

\section{Introduction}

Stress can be defined as a process in which environmental demands strain an organism's adaptive capacity, resulting in both psychological and biological changes that could place a person at risk for illness. ${ }^{(1)}$ The relationship between stress and illness is complex and ambiguous. The critical factor associated with stress is its chronic effect over time. Research shows that almost every system in the body can be influenced by chronic stress. ${ }^{(2,3)}$ Exposure of an organism to any of a variety of stressors markedly activates the sympathoadrenal and hypothalamic-pituitary-adrenocortical systems; and a "stress syndrome," according to concepts proposed by Langley, Cannon, and Selye, maintains homeostasis in emergencies such as "fight or flight" situations, but if the stress response is

*Corresponding author: Marina N. Ivashchenko, $P h D$ Department of Physiology and Biochemistry of Animals, Nizhny Novgorod State Agricultural Academy, Nizhny Novgorod, Russia. E-mail: kafedra2577@mail.ru excessive or prolonged, any of a variety of clinical disorders can arise. ${ }^{(4,5)}$

There are many objective ways to measure human stress responses. Along with an evaluation of the activity of the hypothalamic-pituitary-adrenal axis biomarkers, the search for other methods, which could be easily used in any medical laboratory, is of current importance. Our study revealed that the electrophoretic mobility of red blood cells (RBCs) is an effective criterion of the severity of the organism's stress reaction to extreme effects. ${ }^{(6)}$ Changes in the electrokinetic properties of $\mathrm{RBCs}$ can be considered as a response to the stress factor that is associated with consecutive activation of the basic humoral and endocrine systems. Thus, a decrease in the electrophoretic mobility of RBCs is determined by the activation of the sympathoadrenal system whereas its increase is determined by the activation of the pituitary-adrenal system..$^{(7)}$

It has been shown that the stress influence is accompanied by a high concentration of glucocorticoids, which may disturb the secretion of pro-inflammatory interleukins (interleukin $1,12, \mathrm{TNF} \alpha$, interferon- $\gamma){ }^{(8,9)}$ In addition, it may provoke the 
apoptosis of activated T-and B-cells, and it drives excessive activation to the limitation of the immune system. Sometimes, it may drive the system to a pathological immunodepression. ${ }^{(10)}$ The suppression of cellular immunity is accompanied by the appearance of cytogenetic abberant cells. ${ }^{(11)}$ In this regard, it is very important not only to assess the degree of involvement of stress-realizing systems but also to define the genotoxicity of the reaction caused by the inclusion of these systems.

Currently, the micronucleus test (MT) is a non-invasive, simple and accessible method of assessing DNA damage. ${ }^{(11)}$ It has been shown that MT is not less sensitive than the test of chromosome aberrations in bone marrow cells of animals, but it is less labour-intensive. The cytomorphologic research of buccal epithelium allows assessing the processes of epithelium proliferation and differentiation, the degree of inflammation, cell atypia, and nuclear polymorphism, as well as cytogenetic changes. ${ }^{(12)}$

The purpose of this study was to investigate the electrophoretic mobility of RBCs, cytomorphological and cytogenetical indices in exfoliated buccal epithelial cells of rats during the development of stress reaction.

\section{Materials and Methods}

Experiments were carried out on 60 white non-pedigree pubescent rats weighing 180-220 g. Animals were divided into 4 equal groups. For stress modeling, the animals of Group 1 received a single intraperitoneal injection of epinephrine hydrochloride solution $(0.1 \mathrm{mg} / \mathrm{kg})$, and animals of Group 2 received injections for 3 days of the experiment. The animals of control Group 3 received a single intraperitoneal injection of physiological saline solution, and those of Group 4 received injections for 3 days.

Blood samples were taken from the sublingual vein in 1 hour, 1 day, and 7 days after the epinephrine injection. Micronuclei (MN) identification in exfoliated buccal epithelial cells was performed 7 days after the epinephrine injection, considering the release of basal cells to the surface. ${ }^{(13,14)}$

The RBC electrophoretic mobility level was measured by the microelectrophoresis method. ${ }^{(15)}$ RBCs were washed three times with $0.9 \% \mathrm{NaCl}$ and collected by centrifugation. The cell suspension was made with $10 \mathrm{mM}$ tris hcl buffer $(\mathrm{pH}=7.4)$ and after that the RBC electrophoretic mobility was measured by registering the $100 \mathrm{mkm}$ rbc transmission time in tris hcl buffer with $\mathrm{pH}$ of 7.4 and amperage of $12 \mathrm{MA}$. RBC electrophoretic mobility value was defined using the formula: $\mathrm{U}=\mathrm{S} / \mathrm{T} \times \mathrm{H}$, where $\mathrm{S}-\mathrm{a}$ distance to which the cells moved, $\mathrm{T}$ - time, $\mathrm{H}$ - a gradient of electric potential. The value of potential gradient was determined using the formula: $\mathrm{H}=\mathrm{I} / \mathrm{g} \times \chi$, where I - amperage, $g$ - chamber cross section, $\chi$ - electrical conductivity of the media.

The exfoliated buccal mucosal cells were scraped using a spatula, and cytosmears were stained with Giemsa. The specimen was analyzed with a microscope AXIOSTAR PLUS (Carl Zeiss, Germany), zoom $16 \times 40$ and $16 \times 100$. The number of cells with MN was counted. No more than 1000 cells were examined. The analyzed epithelial cells were wellexpanded, not damaged, and without monolayer deposition.
The cells having numerous microorganisms on the surface were excepted. MN were identified as round chromatinic bodies with a continuous smooth edge along with membrane and having the color of the same intensity as that of the main nucleus. Besides the binuclear cells, cells with anomalous nuclei, karyopyknosis, karyorhexis, anad karyolysis were also analyzed..$^{(16)}$

Animals were housed in keeping with the rules for good laboratory practice. Experiment was performed in accordance with the Guide for the Care and Use of Laboratory Animals (the institute of Laboratory Animal Resources, 1996) and with approval of local Ethics Committee.

Statistical analysis was performed using the statistical software «Statistica». (v6.0, StatSoft, USA). The Shapiro-Wilk test was used in testing for normality. Baseline characteristics were summarized as frequencies and percentages for categorical variables and as mean \pm SEM for continuous variables. Student's unpaired t-test was used to compare two groups for data with normal distribution. A value of $P<0.05$ was considered statistically significant.

\section{Results and Discussion}

The obtained results are represented in Table 1. Both the single and the repeated adrenalin injections provoked a decrease in the level of RBC electrophoretic mobility. In Group 1, the maximal decrease in this parameter was found 1 hour after the beginning of the experiment, but it was restored by the seventh day of the observation. The repeated adrenalin injection provoked the maximal decrease of this index in the first day of the experiment. By the end of the first week, the index had increased by $40 \%$ in comparison with the first day of the experiment. The RBC electrophoretic mobility did not achieve the value of the control group.

Table 1.

Dynamic of RBC electrophoretic mobility index change ( $\mu m \mathrm{~cm} \mathrm{~B}^{-1} \mathrm{c}$ ) under different kind of influence

\begin{tabular}{|l|c|c|c|}
\hline \multirow{2}{*}{ Group of animals } & \multicolumn{3}{|c|}{ Period after the influence } \\
\cline { 2 - 4 } & $60 \mathrm{~min}$ & 1 day & 1 week \\
\hline Group 1 & $0.72 \pm 0.08 *$ & $0.83 \pm 0.09 *$ & $0.94 \pm 0.07$ \\
\hline Group 3 & $1.02 \pm 0.02$ & $1.07 \pm 0.03$ & $1.00 \pm 0.03$ \\
\hline Group 2 & $0.67 \pm 0.02 *$ & $0.54 \pm 0.03 *$ & $0.76 \pm 0.02 *$ \\
\hline Group 4 & $1.04 \pm 0.02$ & $1.02 \pm 0.04$ & $1.00 \pm 0.04$ \\
\hline$*-P_{1-3}<0.05, \wedge-P_{2-4}<0.05$ &
\end{tabular}

The results of the RBC electrophoretic mobility study were identical to the findings that we received earlier when studying different kinds of stresses. ${ }^{(17)}$ A literature review shows that the $\mathrm{RBC}$ electrophoretic mobility index decreases if there are some pathologies, such as chronic kidney disease, chronic brain ischemia, respiratory diseases, ischemic heart disease, or oncological diseases, as well as all kinds of intoxications. It was noted earlier that a decrease in RBC electrophoretic mobility 
was associated with an increase in cell adrenoreactivity whereas the increase in $\mathrm{RBC}$ electrophoretic mobility was combined with an increase in cortisol concentration. Our study revealed that RBC electrophoretic mobility increased, after its primary decrease, more intensively in Group 2 than in Group 1 . These data may be interpreted as a more considerable increase of endogenous cortisol concentration in the blood as a response to the repeated adrenalin injections. At the same time, it is well-known that the higher level of glucocorticoids provokes increasing the number of RBCs with chromosome aberrations. ${ }^{(17)}$ This was discovered in the analysis of buccal epithelium in our study.

The cytogram analysis in the experimental groups showed that there were fewer normal cells and more cells with signs of cytological and chromosomal abnormalities, in comparison with the control groups.

The investigation of the animals of Group 1 revealed that the buccal cells had one or several micronuclei. The micronuclei were represented as oval or circular nuclear-like substances with smooth edges. We found a significant excess of MN in Group 1 (by 15\%) compared to Group 3. Single cells with fragmented nuclei were observed. Their contours were without any spatial orientation. Cells with the initial stage of nuclear destruction, cells with chromatin condensation (corrugated nucleus with condensed chromatin) and cells with reniform vacuoles were frequently observed. The animals of the experimental groups had more cells with condensed chromatin (by 10\%) and reniform vacuoles (by $43 \%$ ) than animals of the control groups $(P<0.05)$.

The revealed forms of cell necrosis make evident the destructive changes in the nuclear membrane and the disturbance of its barrier and transport functions. Karyolysis or nuclear dissolution represents an advanced stage of apoptosis and necrosis. ${ }^{(13,16)}$ We did not find any statistically significant difference in the frequency of cells with karyolysis between the animals of the experimental and control groups. However, a significantly increased percentage of cells with initial signs of necrotic cell death in animals of the experimental group confirmed the development of stress reaction.

Karyopyknosis is a natural form of buccal cell apoptosis. The difference in the number of apoptotic cells in the experimental and control groups was not statistically significant. This proves that the natural mechanisms of buccal cell destruction remain safe.

Analysis of the cytograms in Group 2 showed that the number of cells with MN was greater by $25 \%$ than in Group 4. This difference means that there are pathological changes in buccal epithelium structure and a disturbance of the stability of genetic material. Epitheliocytes in animals of the experimental group had a decreased size due to a reduction in cytoplasm volume. We found many epitheliocytes with signs of the late stage of nuclear destruction (karyopyknosis, karyorhexis and full karyolysis) $(P<0.05)$.

The analysis of cytological and nuclear disturbances in animals of the experimental groups showed that the cytogenetic disturbances (cells with micronuclei, cells with atypical nucleus) and cells with the initial stage of nuclear destruction (chromatin condensation) predominated in Group
1. Cells with signs of of karyopyknosis, karyorhexis and full karyolysis were identified to a greater extent in Group 2. The analysis of correlation between cytomorphological and cytogenetical indices of buccal epitheliocytes and RBC electrophoretic mobility revealed that the intensity of stress influence determinated the intensity of nuclei destruction. These effects are probably caused by the immunodepressive effect of highly intense stress. The compromised immune system can neither recognize nor eliminate the genetically disturbed epithelial cells; it contributes to the accumulation of disturbed cells and to the disturbance of cytogenetic stability. ${ }^{(11)}$

\section{Conclusion}

Our analysis shows that the adrenalin influence provokes at first a decrease in the RBC electrophoretic mobility index, and then an increase. With a single adrenalin injection, the changes in RBC electrophoretic mobility are not so abrupt, with the subsequent development of the adaptive response and reparation of cytogenetic damage. With repeated adrenalin injections, the changes in $\mathrm{RBC}$ electrophoretic mobility are abrupt, and the number of pathological epithelial cells increases.

\section{Conflict of interest}

The authors declare that they have no competing interests.

\section{Sources of Funding}

This study was supported by the Russian Foundation for Basic Research, research project No. 18-016-00195.

\section{References}

1. Cohen S, Kessler RC, Gordon LU. Strategies for measuring stress in studies of psychiatric and physical disorders. In: Cohen S, Kessler RC, Gordon LU, editors. Measuring stress: A guide for Health and Social Scientists. Oxford: Oxford University Press; 1995.

2. Oken BS, Chamine I, Wakeland W. A systems approach to stress, stressors and resilience in humans. Behav Brain Res. 2015;282:144-54. doi: 10.1016/j.bbr.2014.12.047.

3. Maslova MN. [Molecular mechanisms of stress]. Ross Fiziol Zh Im IM Sechenova. 2005;91(11):1320-8. [Article in Russian].

4. McEwen BS. Central effects of stress hormones in health and disease: Understanding the protective and damaging effects of stress and stress mediators. Eur J Pharmacol. 2008;583(2-3):174-85. doi: 10.1016/j.ejphar.2007.11.071.

5. Goldstein DS. Adrenal responses to stress. Cell Mol Neurobiol. 2010;30(8):1433-40. doi: 10.1007/s10571-0109606-9.

6. Krylov VN, Deryugina AV, Pleskova SN. [Electrophoretic mobility and morphometry of the rat erythrocytes at the stress effects]. Sovremennye Tehnologii v Medicine. 2010;4:23-7. [Article in Russian].

7. Krylov VN, Deriugina AV, Konstantinova AI. [Electrophoretic mobility and activity of Na,K-ATPase of erythrocytes in rats under stress]. Ross Fiziol Zh Im IM Sechenova. 2014;100(11):297-302. [Article in Russian]. 
8. Dunn AJ, Ando T, Brown RF, Berg RD. HPA axis activation and neurochemical responses to bacterial translocation from the gastrointestinal tract. Ann NY Acad Sci. 2003;992:21-9.

9. Holland JW, Pottinger TG, Secombes CJ. Recombinant interleukin-1 beta activates the hypothalamic-pituitaryinterrenal axis in rainbow trout, oncorhynchus mykiss. J Endocrinol. 2002;175(1):261-7.

10. Korochkina EA. [Morphofunctional status of testis and adrenal glands of rats in stress-related conditions]. Genetics and breeding of animals. 2014;3:28-31.[Article in Russian].

11. Levinsky MV, Kalaev VN, Butorina AK. [The analysis of the contents of cells with micronuclei in buccal epithelium and the level of serum antibodies among children and adults living in various areas of the city of Kishinev]. Kursk Scientific and Practical Bulletin «Man and His Health». 2008;2:12-7. [Article in Russian].

12. Vovk YR, Linnik MS, Morozova EN, Morozov VN. [The Structural Features of the Buccal Epithelium in Indian Female Students in the Different Phases of the Menstrual Cycle]. J Anat Histopathol. 2016;5(3):13-16. [Article in Russian].
13. Yurchenko VV, Podolsk MA, Ingel FI, Krivtsova EK, Belyaev NN, Nedachin AE, et al. Micronucleus test in human buccal epithelial cells. In: Multiorgan micronucleus test in environmental and hygienic studies. M.: Genius; 2007. M.: Genius, 2007. [In Russian].

14. Deryugina AV, Ivashchenko MN, Ignatiev PS, Samodelkin AG, Belov AA, Gushchin VA. The evaluation of genotoxic effects in buccal epithelium under disorders of adaption status of organism. Russian Clinical Laboratory Diagnostics. 2018;63(5):290-92.

15. Kozinets GI. Blood tests and urine tests. Clinical significance. M.: Prakticheskaya meditsina; 2008. [In Russian]. 16. Kalaev VN, Nechaeva MS, Kalaeva EA. Micronucleus test in buccal epithelium of the human oral cavity. Voronezh: Izdatel'skij dom VGU; 2016. [In Russian].

17. Kamshilova TB, Mikryakov VR, Mikryakov DV. [The effect of cortisol analogue and transport stress on the incidence of micronuclei in peripheral erythrocytes of the sterlet (Acipenser ruthenus L)]. Inland Water Biology. 2013; 2:94-6. [Article in Russian]. 